\title{
Correction to: Impacts of internal variability on temperature and precipitation trends in large ensemble simulations by two climate models
}

\author{
Aiguo Dai ${ }^{1}$ (D) . Christine E. Bloecker ${ }^{1,2}$ \\ Published online: 10 April 2018 \\ (c) Springer-Verlag GmbH Germany, part of Springer Nature 2018
}

\section{Correction to: Climate Dynamics \\ https://doi.org/10.1007/s00382-018-4132-4}

Please note that the CanESM2 large ensemble of simulations for the twenty-first century was carried out under the RCP8.5 forcing scenario (same as the CESM1 simulations), not under the RCP4.5 scenario as it was incorrectly stated in the paper. Thus, the few discussions in the paper associated with the RCP4.5 scenario should be discarded. This description error does not affect the results and conclusions of this paper.

1 Department of Atmospheric and Environmental Sciences, University at Albany, State University of New York, Albany, NY 12222, USA

2 Present Address: NASA Global Modeling and Assimilation Office, NASA Goddard Space Flight Center, Greenbelt, MD, USA 